\title{
Digitizing Dionysios Solomos' Manuscripts
}

\section{Katerina Tiktopoulou \\ Eleni Petridou}

Vasilis Vasileiadis

\section{Anna Saggou \\ Kostas Theodoridis}

Neograeca Bohemica | $20|2020| \mid 71-87$

\begin{abstract}
This paper focuses on the design principles and features of the 'Digital Solomos' project, a digital edition of the corpus of Dionysios Solomos' manuscripts that is currently being developed at the Aristotle University of Thessaloniki. The digital edition in question will include digital facsimiles of almost all of Solomos' draft manuscripts (provided by the institutes where they are housed) as well as digital tools to enhance the reader's interaction with the digital surrogates and the transcribed text. After a brief overview of the editing traditions developed around the editorial problem of Solomos' unfinished works, the paper focuses on the relationship between the digital edition under development and the groundbreaking diplomatic edition that Linos Politis envisioned and compiled in 1964. The features of the diplomatic digital edition are then described, namely its layout and the options it provides for manipulating the document facsimiles and analyzing the texts contained within them. Finally, the paper's closing section refers to the design and characteristics of the digital genetic edition of Funeral Ode II, a small poem by Dionysios Solomos, which will be the first (experimental) genetic edition to be included within the 'Digital Solomos' project.
\end{abstract}

\section{Keywords}

Dionysios Solomos, draft manuscripts, digital edition, genetic edition, digitization 


\section{Editing Dionysios Solomos' manuscripts: from eclectic to diplomatic to digital}

When the Greek poet Dionysios Solomos died in 1857 , leaving most of his important works unfinished and unpublished, his disciple and friend Iakovos Polylas took up the difficult task of preparing an edition in order to present the poet's work to an audience particularly eager to read the reputedly great poems of a writer that would soon become the national poet of Greece. Unsurprisingly, guided by his consideration that the poet's work should not be belittled by exposing its fragmentation and lack of synthetic elaboration, Polylas worked with the poet's manuscripts carefully and methodically, selecting and combining variants from different stages of the writing process to compile eclectic texts that concealed the work's incompleteness. ${ }^{1}$

Polylas' intervention - however intelligent and effective it may have been gave the poet's incomplete work its final shape, and heavily determined its reception. To this day, Solomos' work is still predominantly read through the form it took in Polylas' edition, even though it has been shown that his eclectic version of Solomos' incomplete texts diverges from those in his autographs.

As early as 1938, Linos Politis, who later became a professor at the Aristotle University of Thessaloniki, drew our attention to the importance of Solomos' autographs. ${ }^{2}$ In a vivid public debate over an eventual new, revised edition of Solomos' work, ${ }^{3}$ Politis opposed the creation of another eclectic edition, offering an enlightening description of Solomos' editorial problem. The fragmentation and incompleteness of his work, Politis noted, should not be confused with those of an ancient Greek, Latin or medieval work. They should instead be attributed to the author himself, as his tormented autographs testify; the various versions of his texts that perplex our reading are not textual variants but author variants, the result of Solomos' style of working, of his doubts and his hesitations. The first editor attempted to construct a readable text by choosing - according to his aesthetic agenda - the 'best' version from among the several, often equivalent versions of Solomos' incomplete texts. This, argued Politis, results in substituting the poet, something that cannot be seen as scientifically legitimate. Instead, Politis boldly proposed that the facsimile and diplomatic edition of the poet's manuscripts should be the only edition that can provide an 'authoritative text' in the case of Solomos' incomplete work. This was

1 Polylas (1859).

2 Politis (1938).

3 Mastrodimitris (1996). 
an important paradigm shift in the history of Modern Greek textual studies, as the dominant paradigm of the scholarly critical edition was being rejected as inappropriate for Solomos' case, and a different approach to the textual problems of modern texts was being proposed and eventually applied in the innovative edition of the poet's manuscripts a few decades later.

The two-volume facsimile and diplomatic edition of Solomos' manuscripts, which was finally realized in $1964,{ }^{4}$ has proved extremely fruitful for Solomos' studies, offering scholars a solid and objective basis for their research. Many important monographs and articles have been published since, and the ever-growing bibliography on Solomos has contributed to a better understanding of the poet and his work.

As far as the textual problem of Solomos' incomplete work is concerned, the diplomatic edition of his autographs offers, as Politis noted, the only authoritative text possible. However, it is a text that is accessible only to specialists and scholars, due to the poet's bilingualism (his use of both Greek and Italian), his orthographic habits, and the 'clumsy' and fragmentary way in which the text is elaborated within the manuscripts. In order for these texts to be addressed to a wider audience, some kind of editorial mediation is crucial. But what kind of editorial mediation could be effective without being misleading, i.e. be useful to the reader while respecting the state of these incomplete works?

The transition from Solomos' manuscripts' diplomatic edition to an edition that could provide the general reader with an 'accessible' but also 'reliable' text of the incomplete Solomian work (without misleading textual interventions) was achieved in 1977-1978, and marked a second important (and decisive) paradigm shift within the tradition of Modern Greek textual studies.

The new proposal was formulated by Eleni Tsantsanoglou ${ }^{5}$ who, when facing the problem of how to present a group of incomplete Solomian texts for the first time, went on to redefine the scope of such a presentation. Its purpose would not be to offer a definitively clear text, as this does not exist, but to make the work's creative process explicit, both through reconstruction and a 'meaningful' - within the limits of the editor's understanding - presentation of all its elaborated material, from the moment of the composition's conception through to its abandonment.

As her aim was to present thoroughly and in detail (in Modern Greek, ava-

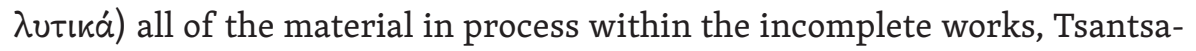
noglou called this new method 'analytical', unaware of the almost simultaneous

4 Politis (1964).

5 Tsantsanoglou (1982). 
development of a similar hermeneutical and editorial approach in France by Louis Hay and his team, ${ }^{6}$ with which her approach shared a number of elements, although also many differences. ${ }^{7}$ This approach is of course genetic criticism (in French, critique génétique), which has become (objections aside) an established and valid scientific method of approaching, interpreting and editing an author's archive.

Today, the average reader wishing to read Solomos' incomplete work must choose between the eclectic editions prepared by Polylas (and more recently by other scholars, since the dominant paradigm is still active), and the competing paradigm of the analytic/genetic editions which has been applied to a - currently small - number of incomplete Solomian works. The former mainly satisfies the convention of reading a completed work, without worrying if the texts are significantly different to those left by the poet in his manuscripts. The latter, which is more demanding but also more rewarding, places readers in the poet's workshop and helps them to follow the creative composition of his works based on the available manuscript evidence.

Developed within the context of the editing paradigms and traditions described above, the creation of a digital edition of the Solomian draft manuscripts presented here is certainly part of a rising 'trend' of our time, which encourages the digitization of manuscripts, rare books and other types of archival material in order to make them open and accessible to both scholars and the general public. This has several benefits: readers/users do not have to travel to the manuscript's location, the fragile manuscript's condition is not threatened, and preservation standards are respected. The process of digitizing manuscripts, rare books and archival material is usually conducted by libraries, public repositories and private collections, that is, traditional institutions that have been called upon to redefine their identity and function in the modern digital age. However, in the case of Solomos' Digital Archive project, which comes from the academic field and is the first similar endeavour in Greek textual studies, there are many other reasons to follow this trend. The goal of the project is to prepare a new, digital environment for reading Solomos' manuscripts, where the precious testimonies of his works can be fully accessed and researched with digital tools.

6 Genetic Criticism in France began as a scientific interest to preserve and make use of authors' manuscripts and archives, 'le patrimoine écrit', and within a short period of time developed into a vibrant branch of French literary criticism that was at the time mostly dominated by structuralist approaches. Deppman - Ferrer - Groden (2004: $1-16)$.

7 Tiktopoulou (2015: 118-121). 
The project of course recognizes the unique importance of Solomos' manuscripts and shares the concern for their preservation. It is undoubtedly useful to remember that there can be no identification between the material manuscript and its digital (or printed) surrogate. Neither the print edition nor the digital surrogate are a substitute for the material manuscript, as in order to fully inspect and evaluate the material aspect of the document (its weight, colour, quality, and physical state), one needs to be able to inspect it in situ, to leaf through its pages, to 'touch, feel and smell' it instead of exploring it on a two-dimensional screen using forward and back buttons.

Even if "only visual aspects are represented in a digital surrogate, and even then in a mediated manner, converting a three-dimensional perception to a two-dimensional one, possibly distorting the size and colour of the original object", ${ }^{8}$ it nevertheless seems that each of the different approaches to the manuscript - namely on the spot, through a printed version and a digital representation - conveys a different awareness of it, each with its own advantages and drawbacks. Having spoken of the limitations of digital access, we will now focus on some of its benefits, specifically those that apply to the Solomos manuscripts and the digital environment carefully designed and created by the Solomos' Digital Archive project. These include the possibility of simultaneous and/or sequential access to surrogates of manuscripts located in distinct, distant repositories (which was already the case with Politis' diplomatic edition); ease of access at any time; the convenience of an unprecedented management that enables zoom, flipping, rotation etc; and a parallel reading of the original manuscript and its transcription. These are some of the features of the digital edition that are described in the next sections in more detail.

The access to the digital version of Solomos' working manuscripts is addressed and proposed as a new experience of reading manuscripts and texts, leading to new findings and new questions. We may now consider the goals, techniques and implementation of this project.

\section{Digitizing the 1964 edition or redesigning a digital documentary edition?}

During the past few decades, the transition to the digital medium has renewed scholarly interest in designing and producing editions of texts in new, digital environments. New practices that appear to incorporate past editing traditions, as well as new theoretical models, have emerged in one of the most dynamic

8 van Lit (2019: 62). 
areas of the diverse academic field, entitled Digital Humanities: Digital Scholarly Editions. ${ }^{9}$ The abundance of choices and possibilities to store and represent textual and document data on the web offered to editors by the new medium has resulted in the production of a number of digital edition projects, many of which are document-oriented, placing the emphasis not on the edited text (or not only), but also on the materiality of its medium: the manuscripts. ${ }^{10}$ This new medium seems convenient and flexible enough to host editions that do not attempt to present the readers with a stable version of the text, but predominantly concentrate on providing them with the tools required to approach the textual material in the context of its production, attributing equal meaning to the material aspects of its source, such as writing tools and hands, the topographical arrangement of the text on the writing surface, additions and cancellations, etc. This type of edition which past editing traditions viewed as 'non-critical' - is aligned with a growing interest in the cultural context of text production, the history of books and writing, but also with scholarly traditions that approach textual genesis and variation, and appears to be the most vibrant branch of digital text editing today. ${ }^{11}$

A strong theoretical basis and sophisticated editing practices have been formed in recent years through the production and publication on the web of a number of digital documentary editions. ${ }^{12}$ Most of these projects have been driven by the aim to provide the research community with digital - therefore easy and remote - access to the entirety of an author's manuscripts, which are usually scattered across various locations or repositories. In most cases, the environment of the digital edition enables the researchers to explore the manuscripts' content for the first time through digital transcriptions, as well as to consult with the material aspects of the document through digital facsimiles. This is achieved without visiting the library or institution that holds the

9 Sahle et al. (2020).

10 Pierazzo (2011).

11 Eadem (2015: 74-83).

12 Early examples of such editions are: Jane Austen's Fiction Manuscripts: A Digital Edition, edited by Kathryn Sutherland, www.janeausten.ac.uk; The Walt Whitman Archive, edited by Matt Cohen, Ed Folsom and Kenneth M. Price, Center for Digital Research in the Humanities at the University of Nebraska-Lincoln, www.whitmanarchive.org; The William Blake Archive, edited by Morris Eaves, Robert N. Essick and Joseph Viscomi, www.blakearchive.org. Other more recent, influential examples: Samuel Beckett Digital Manuscript Project, edited by Dirk Van Hulle and Mark Nixon, Center for Manuscript Genetics at the University of Antwerp, www.beckettarchive. org; The Shelley-Godwin Archive, edited by Neil Fraistat, Elizabeth Denlinger, and Raffaele Viglianti, www.shelleygodwinarchive.org; Faust edition, edited by Anne Bohnenkamp, Silke Henke and Fotis Jannidis, www.faustedition.net. 
document, and without taking the scholarly effort to produce transcriptions for their own personal use (as would have been the case only a few decades ago).

The 'Digital Solomos' project has been somewhat different from the outset, as the objectives and design of the edition were considerably determined by the pre-existence of the print diplomatic edition of Solomos' manuscripts in 1964 which, as previously mentioned, had already provided access to almost all of the author's draft manuscript corpus. The first volume of this edition included excellent facsimiles ${ }^{13}$ of almost all the surviving draft manuscripts in the author's archive, while the second provided diplomatic transcriptions that were based both on Iakovos Polylas' thorough readings and Linos Politis' excellent paleographic skills. The 1964 edition was revised and republished in separate, smaller and more practical volumes between 1998 and $2012^{14}$ and remains the most valuable tool and stable point of reference for any researcher in the field of Solomos' studies, or the field of Modern Greek literary studies in general.

It was thus clear that a new, digital edition of Solomos' manuscripts would have to take into account the characteristics and achievements of the previous, printed edition and attempt to align itself with the reading habits and practices established by it. At the same time, practices in the field of digital documentary editions have since shaped new editing models and tools, opening up new possibilities and functionalities for text and manuscript editions. It was clear that the venture of preparing a digital edition for Solomos' manuscript corpus would have to respond to both calls: to incorporate the features that would enable an easy transition to the digital version for past users of the printed edition, but also to explore and integrate valuable tools from the newly shaped tradition of digital documentary editions.

The digital version of the edition shares many of the objectives, as well as the theoretical background, of the printed edition. Its main aim is to provide the readers with facsimiles - now digital ${ }^{15}$ - of the documents and their transcriptions in a visualization that attempts to reproduce some of the material aspects of the text and document: the topographic arrangement of the text on the writing surface, additions and deletions, and different writing hands. The content and editorial model of the printed edition are maintained and enriched

13 The technology used for the production of these facsimiles achieved a resolution and clarity that makes them still valuable today, as the passage of time deteriorates the condition of the manuscripts. Tiktopoulou - Politi - Kechagioglou - Tsantsanoglou (1998-2012).

15 The holding institutes have agreed to grant digital facsimiles to the editors for the purpose of the digital edition. The manuscripts were not photographed anew, as existing digital facsimiles were used. 
in the digital edition. The documents included in the printed edition will gradually be published in the digital version, which will eventually include documents that were not part of the previous two versions of the printed edition. ${ }^{16}$ Accompanying material, such as notes and critical apparatus, will also remain and be updated according to recent bibliography.

In the 1964 edition, a great deal of editorial effort was made to reproduce some of the material aspects of the document, as these are considered meaningful for the interpretation of the writer's decisions during the course of writing. One of the main aims of the digital edition was to maintain and further expand on this consideration for the reproduction of some of the paleographic features of the document that reflect on the interpretation of the writing process. For this reason, in the digital edition, as in the printed edition, facsimiles of the documents are provided, accompanied by transcriptions that reproduce the topographic arrangement of the text on the writing surface. In the digital edition, the facsimile and the transcription of each document page are presented together onscreen, thus offering the reader the opportunity not only to move more freely from studying the text to studying the manuscript (namely its digital surrogate), but also to verify and judge the transcription provided by the editor. Moreover, the digital edition makes use of text-to-image linking tools, which help the readers to better orientate themselves: every time the cursor lingers on a part of the facsimile, the corresponding part of the transcription is highlighted, and vice-versa. This feature is especially useful for heavily revised and densely written pages that trouble even experienced researchers of the poet. For the notebooks, the reader is also provided with the option to leaf through a digital surrogate, a display feature that attempts to reproduce certain aspects of the physical document, such as its thickness and pagination.

In the digital edition, some of the editorial conventions of the two previous printed editions have been abandoned and the diplomatic principle has been expanded to include some more writing features. For example, deletions in the printed edition were marked with two types of square brackets ([ ]), whereas in the digital edition an effort is made to represent them with a variety of styles (a strike-through, a thorough crossing-out) that attempts to follow (as far as possible) the particular way in which the writer chose to delete the text. ${ }^{17}$ In

16 Predominantly manuscripts that are not holographs, or have very few traces of the author's hand.

17 Diplomatic editions tend to vary in the level of diplomatic representation they choose to adopt. Ultra-diplomatic editions make a case for representing the source text as far as typography conventions make it possible. For an example of an ultra-diplomatic 
the case of corrections introduced through overwriting, a popup cloud warns the reader that an underlying writing layer existed before the one displayed on screen. Words or letters cancelled by overwriting had been indicated in the apparatus of the printed edition, which created the impression that these corrections are less significant than others included in the main transcription. In general, an effort has been made to keep the transcription as free from symbols as possible in order to avoid, wherever possible, increasing the interpretational effort required by the reader.

An important feature of the printed edition that is maintained in the digital version is the reference system. In the printed edition, references to the documents and their page numbers are marked at the bottom of the page using the traditional paleographic reference system: for example, Zakúv७ov ap.10, $\varphi^{\alpha}{ }^{\alpha}$ is the first page of the notebook kept in the Museum of D. Solomos and Eminent People of Zakynthos that bears the number 10. At the same time, the printed edition featured a continuous numbering of all the manuscript pages so that, for example, the aforementioned page from notebook Z1o could also be referenced as AE135, a reference that can easily be decoded by past users of the printed edition as referring to page 135 of Aftografa Erga. The second reference system, which is based on continuous page numbering, is also kept in the revised version of the printed edition, despite the fact that the documents are no longer presented in the same volume. In the digital edition, it was important to keep both reference systems in order to align with the habits and expectations of readers who were already experienced users of the printed edition. At the same time, a third reference system is introduced for the notebooks, with a continuous numbering of the pages that starts at page 1 for each notebook. This last system is considered important because it corresponds to the readers' broader reading habits, helping them to orientate better in the case of multi-page documents.

The printed edition has served as a model and base for the transition to the digital medium. The production of the digital edition was based on the scanning and application of OCR technology to the printed edition, after which the text was revised by editors, and text-to-image linking technologies were applied. ${ }^{18}$ Great consideration was given to the characteristics and contents of the digital edition in comparison to the printed one. The project began as a digital

edition, see Eliot (1971). For a proposal of an ultra-diplomatic transcription in the context of Solomos' manuscript studies, see Pavlou (2015: 156).

The edition is based on $\mathrm{xml}$ technologies, and the transcription follows the TEI Guidelines for Electronic Text Encoding and Interchange: TEI Consortium (2020). The TEI-xml file of the transcription through which the visualization is produced will be available to users of the edition. 
diplomatic edition that would also include a genetic edition of Funeral Ode II and a concordance for Italian words. ${ }^{19}$ In the course of its development, the editing team decided not only to include tools and materials that were already part of the previous editions (such as indexes of persons and places mentioned and updated critical notes), but also to create additional tools that were now easier to develop due to the full digitization of the manuscripts' text.

\section{Solomos' digital edition as a corpus}

As previously mentioned, the Solomos' Digital Archive project mainly focuses on providing a document-centred digital edition of the poet's manuscript facsimiles and their topographic transcription. Evidently, the full digitization of the manuscripts' text constitutes a text corpus, which, although it does not coincide with Solomos' entire literary work, corresponds to most of it. In fact, it corresponds to his numerous works in progress, which were never completed, and are extremely difficult for the researcher to supervise. The digital edition thus aspires to develop at least some of the useful tools that could facilitate Solomos' readers and researchers to perform advanced searches and quantitative analysis on the corpus, as well as permitting the interconnection of Solomos' corpus with other corpora of Greek and Italian writers of his time, with all the positive consequences that this entails for research and our understanding of his work.

However, in order to provide the readers/users with such sophisticated analytic tools, the project had to take into account some particular characteristics of Solomos' corpus, namely the poet's bilingualism and the orthographic peculiarities in his Modern Greek writing. It is known that Solomos, born on the Ionian Islands at the end of the $18^{\text {th }}$ century, grew up with and used throughout his life two languages, Italian and Greek, as did many of his compatriots. In Solomos' case, his bilingualism is evident even when he composes poems in Modern Greek, as he notes his thoughts on the composition of his poems in Italian and drafts in Italian prose. ${ }^{20}$ In terms of language, a basic characteristic

19 The edition is programmed to include a digital concordance of Italian words. A concordance for the Greek words found in Solomos' works is already available: Kapsomenos - Antoniou - Ladogianni - Stroungari - Triantou (1983) and also (in electronic and printed form) Kapsomenos - Letsios - Mantzios - Papastefanou (2008). Nevertheless, as it is explained here, in the digital edition of Solomos' manuscript corpus the transcriptions are fully searchable both in Italian as well as in Greek or any other language used in the corpus.

20 Mackridge (1994). 
of the Solomos' manuscripts' corpus is thus the co-existence of these two languages, along with a continuous code-switching from Greek to Italian and vice versa. Another important characteristic of Solomos' manuscripts is his inconsistent spelling when composing his verses in Modern Greek, as he often ignored the spelling rules or/and was indifferent to the spelling conventions of his time. ${ }^{21}$

Undoubtedly, these peculiarities can undermine attempts to approach the digital corpus with distant reading tools, as well as its interconnection with other corpora. In order to address this problem, the project team applied machine transliteration to unify spelling variants and give a transliterated form of the corpus, rendering it machine readable and fully searchable. ${ }^{22}$ Thus, upon each search performed by the reader/user of the edition, the term requested, whether written in Greek or Italian or using alphabetic symbols from both writing systems, it is transliterated into Latin alphabetic symbols and compared to the words of the corpus in their transliterated form. For example, if the user/reader enters the term ' $\pi \rho \omega^{\prime \prime \prime}$ ', it will be transliterated into 'proi' and

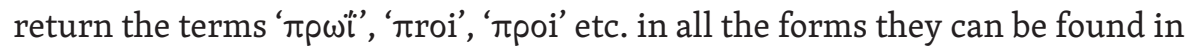
the corpus.

Having overcome the problem of the linguistic peculiarities of Solomos' corpus, we were able to explore and integrate valuable search tools. Persons names, place names, the titles of Solomos' works and quotations from works by other writers are all encoded in the xml transcription in order to enrich the edition with respective indexes, so that users can easily locate the information they seek, interlinked with the digital facsimile and the transcription of the page where the requested term appears. Additions and deletions made by the poet during the writing process, as well as the re-elaborations/revisions of the texts, were also encoded.

The reader/user can thus inspect and search the corpus with the help of Indexes for: (a) people and (b) places mentioned; (c) the titles of Solomos' works; and (d) quotations from the works of others that are explicitly or implicitly contained in the autographs. The search results are refined according to predefined criteria/filters, relevant to the corpus' features. These include: (a) the specific manuscript and (b) work in which the result appears; (c) the different writing hand/hands to which the texts can be attributed (since various scribes

21 See especially Mackridge (1994), Athanasopoulou (2000), Minniti-Gonias (2002).

22 The transliteration method applied to the corpus and its results were presented by the research team in the 2019 DH Budapest Conference (Tiktopoulou, K. - Theodoridis, K. - Vasiliadis, V. - Petridou, E. - Saggou, A.: Building distant reading tools for handling variations/polytype in spelling: the case of the 'Digital Solomos' project). 
and copyists, identified or as yet unknown, have worked on Solomos' manuscripts); (d) if it is located within an original Solomian text or in a translation or quotation; and (e) whether it is the initial text or the result of a later addition, or if it was deleted. Some of these filters lead to the heart of the Solomian case, the very core of his poetics, and can help to answer questions about language usage, support an analysis of the writing process, as well as open up new avenues of research by allowing entirely new research questions and methods. Naturally, the use of the transliterated corpus inside the digital edition allows users to search for any word, whether it is written in Greek, Italian or in another language. However, emphasis has been placed on the Italian, as there is still no supervision of the Italian language used by the poet. Therefore, the Italian words are listed in alphabetical order, as well as placed in context. The search results always lead back to the manuscripts themselves and to their transcriptions.

\section{Digital and genetic}

The current version of the digital edition of Dionysios Solomos' manuscripts is also planned to include a digital genetic edition of Funeral Ode II, a short poem that was elaborately sketched and revised by the poet, but ultimately left unfinished. ${ }^{23}$ The genetic edition draws its material from the diplomatic edition, but the text and document have been re-organized and re-annotated for the purposes of the genetic venture that aims to reveal the chronology of the manuscript, and ultimately the course of the writing. The editors believe that genetic editing ${ }^{24}$ offers the theoretical background, proper tools and established practices for preparing and providing the reader - whether expert

23 Funeral Ode II was published as a poem of three stanzas within Iakovos Polylas' edition of Evriskomena in 1859. Since then, research has revealed that it was actually planned to be a poem of fifteen stanzas. Careful study of notebook AA1 has shown that Solomos worked quite intensively on six stanzas, drafting Greek verses, but also elaborating the poem in Italian prose, before dropping the entire project. Tiktopoulou (2003).

24 Genetic edition/genetic editing is one of the outcomes of genetic criticism. It refers to an edition - conceived and implemented initially in print - that presents, in the chronological order of the writing process, every surviving document that is related to the genesis of a work or a writing project. Grésillon (1994: 188). Genetic editing became more popular in the digital paradigm. Digital genetic editions are a mode of digital scholarly editing that emphasizes the materiality of writing and attempts to reproduce the writing process as opposed to editing models that focus on the establishment of a single reading text. Pierazzo (2015: 78), Gabler (2016: 65-67). In order to address the needs of such editions the TEI Guidelines have included since $2011 \mathrm{a}$ module for genetic editing. 
or motivated - with a suitable environment to access the genesis of the work and interact with its drafts. Furthermore, as previously mentioned, the editors of the project believe that genetic editing, represented in Modern Greek textual criticism by the Analytic Editing School, allows the reader to approach Solomos' major unfinished works in a way that does not disguise or hide the fragmentary state in which they have been delivered to us. Genetic editions, instead of resorting to the constitution of an eclectic reading text, narrate the work's writing progression by presenting the different versions of the text that were created by the author's shifting intentions during the writing process.

In the (separate but not isolated) environment of the genetic edition under development, readers will have the opportunity to flip through the facsimiles of notebook AA1 and stop whenever they choose to study the genesis of the work at every two-fold page, using the tools provided by the editors. The tools which the project team is considering and experimenting with include:

a. An animated presentation of the course of writing as it is assumed to have been developed on the double-page writing surface..$^{25}$ This feature enables the user to make the various writing zones appear in the order in which they were written by clicking on the writing surface. This animation tool allows a more intuitive and user-guided presentation of the writing process, which demands less effort from the reader and constitutes a playful way of interacting with the document and the text within, in a way that attempts to replicate the movements of the author's hand on the writing surface.

b. An audio guide that supports the effectiveness of the animated presentation by providing the reader with the option of listening to - instead of reading - brief editorial comments on the genesis of the work. The aim of the audio guide, attached to the zones of the facsimile, is to inform the reader of the role that each specific segment plays in the course of the writing, highlighting the writer's decisions and focusing on the most important writing events that occur within each writing surface.

c. A presentation of alternative versions of the writing sequence, where there is editorial ambiguity. In cases where the interpretation of the writing sequence is uncertain and more than one writing sequence appears to be possible, the readers will be provided with the opportunity to explore both options and examine for themselves the probability of each writing scenario.

d. 'Clean' reading texts that represent different stages of the writing course. This option allows the reader to resort to a 'clean' reading text at every stage of

25 The animation tool being developed draws on the experience and code of the 'Proust Prototype'. André - Pierazzo (2013). 
the genesis, and to become acquainted with the different textual forms that represent the shifting authorial intention during the course of writing.

The experimental version of the genetic edition that has been implemented and presented by the team ${ }^{26}$ is intended to be further developed in order to help test the functionality and effectiveness of the tools described.

The genetic edition goes a step beyond the diplomatic edition, as by using the mediation of the editor it allows the reader to not only access the contents of the manuscript but also to interpret the marks that the author's hand left on the paper, as part of a process that leads to the completion of the writing project or as in our case - to its abandonment. On the other hand, although the interaction with and perception of the writing process requires ergodic effort, it is also a playful experience that triggers the readers' curiosity while simultaneously challenging their intellectual skills. In designing the genetic edition of Funeral Ode II, the editors aim to support the readers' experience with multimodal tools that reduce interpretation through reading to the avant-text, and channel all other information through other media (mainly audio and animation).

After the full implementation of the first genetic edition, that of Funeral Ode II, the project intends to include genetic editions of other unfinished works by Dionysios Solomos. As mentioned above, the diplomatic edition (in print or digital form) is a necessary starting point to give readers access to Solomos' draft manuscripts, or acquaint them with the actual form in which his unfinished works were delivered to us. Genetic editing helps the readers, even those who are non-expert, to go a step further by interpreting the various segments of the manuscript as parts of a writing process that spreads not only across space, but also across time. Thus, through the mediation of the editor, the reader is able to create meaning by reading the avant-text but is also able to identify the writing acts that emerge from it and, once they are placed in chronological order, form a narrative of the work's genesis. ${ }^{27}$

The digital environment as a publishing platform, when compared to print, appears to offer certain advantages as far as scholarly editions are concerned. ${ }^{28}$

26 Aspects of the design and the implementation of the experimental version of the edition have been presented by members of the project team on two occasions: in the ESTS 2018 Annual Conference that took place in Prague (Tiktopoulou, K. Petridou, E.: On displaying textual fluidity in (digital) genetic editions) and in the International Symposium 'Writing and revision stages' that took place in Lisbon in June 2019 (Tiktopoulou, K. - Petridou, E.: Visualizing writing stages in a digital genetic edition: the case of scholarly uncertainty).

27 Rehbein - Gabler (2013).

28 Gabler (2016). 
Digital scholarly editions are generally easier to access, more flexible, user-friendlier and more easily searchable. But their main advantage lies in their potential for hyperlinking, which allows the editor to highlight the interconnections that spread throughout the manuscript and create alternative, non-linear reading paths of the edition. Bringing out and visualizing these interconnections is important to communicate the genetic processes. Moreover, most digital genetic editions function within a wider reading environment that is very often called a 'digital archive', something the edition discussed here also aspires to. This means that the reader, while studying the genesis of a work through the tools provided by the editor, is also free to move back to the 'archive version' ${ }^{29}$ and once again consult the digital surrogate of the manuscript and its transcription, which represent a less mediated edition of manuscript and text. ${ }^{30}$

One could of course also argue that digital scholarly editions, and especially genetic editions that tend to use complicated and sophisticated visualization tools, are at constant risk of being surpassed by new technologies that threaten their future functionality (as is the case with all digital products). Sustainability issues are a challenge in the digital world, due to its inert mutability. The need to establish and follow specific worldwide standards in the development and implementation of digital scholarly editions is a shared preoccupation in the wider community of Digital Humanities. It is thus important for every new project to follow and contribute to the dialogue that helps shape these common standards, and eventually establish a series of good practices in the field that may ensure the future viability of digital projects, or at least the potential future re-usability of the data they produce.

The Solomos' Digital Archive is the first large-scale digital scholarly edition of an important manuscript corpus from the $19^{\text {th }}$ century in the field of Modern Greek literary studies. ${ }^{31}$ The design and implementation of the project faced and still faces - many challenges, arising both from the particular features of the corpus and the lack of any previous experience and bibliography in Modern Greek digital editing. Nevertheless, every effort has been made to comply with established standards and tools, all the while keeping in mind the needs and expectations of the anticipated readers.

29 Sahle (2016).

30 'Less mediated' by no means equals 'not mediated at all'. The project team is, of course, aware that every edition is nothing but a representation of the manuscript and text based on the model created by the editor, and no edition can recreate and fully represent the document and its content.

31 A trial version of Solomos' Digital Archive will hopefully be uploaded by the end of 2020 . 


\section{Bibliography}

André, J. - Pierazzo, E. 2013. Le codage en TEI des brouillons de Proust: vers l'édition numérique. Genesis 36, 155-161 [online]. Available from: https://doi.org/10.400o/ genesis.1159 [16 November 2020].

Athanasopoulou, A. 2000. Provlimata perigrafis kai ermineias ton ellinoïtalikon tou

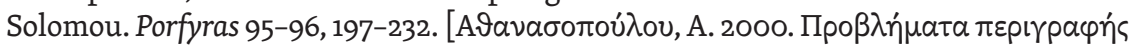

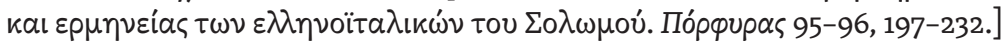

Deppman, J. - Ferrer, D. - Groden, M. (eds.) 2004. Genetic Criticism: Texts and Avant-Textes. Philadelphia.

Eliot, V. (ed.) 1971. T. S. Eliot, The Waste Land. A Facsimile and Transcript of the Original Drafts Including the Annotations of Ezra Pound. New York.

Gabler, H. W. 2016. The Draft Manuscript as Material Foundation for Genetic Editing and Genetic Criticism. Variants 12-13, 65-76 [online]. Available from: https://doi. org/10.4000/variants.299 [2 March 2020].

Grésillon, A. 1994. Eléments de critique génétique. Lire les manuscrits modernes. Paris.

Kapsomenos, E. G. - Antoniou, M. - Ladogianni, G. - Stroungari, M. - Triantou, I. 1983. Lexiko Solomou. Pinakas Lexeon tou ellinoglossou solomikou ergou. Ioannina. [Ka $\psi \omega-$

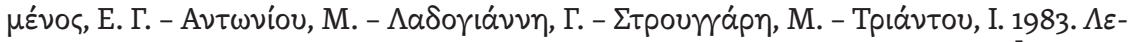

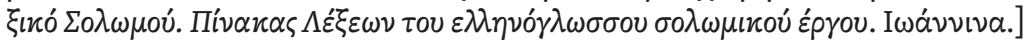

Kapsomenos, E. G. - Letsios, V. - Mantzios, A. - Papastefanou, V. 2008. Dionysios Solomos:

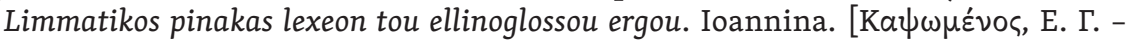

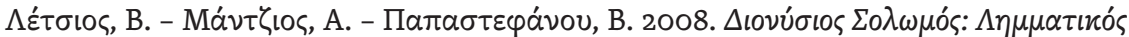

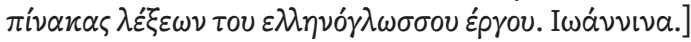

van Lit, L. W. C. 2019. Among Digitized Manuscripts. Philology, Codicology, Paleography in a Digital World [Open Access E-Book]. Available from: https://doi.org/10.1163/ 9789004400351 [2 March 2020].

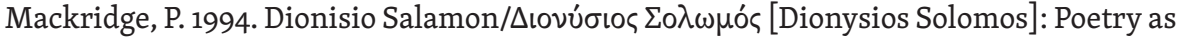
a Dialogue between Languages. Dialogos: Hellenic Studies Review 1, 59-76.

Mastrodimitris, P. D. 1996. Ioannis Sykoutris - Linos Politis: To chroniko mias filologikis

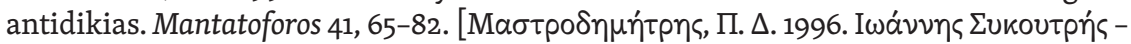

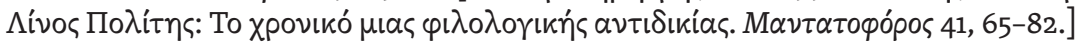

Minniti-Gonias, D. 2002. Protaseis gia mia mellontiki ekdosi enos italoellinikou glossariou tou Solomou. In Thiteia. Timitiko afieroma ston Kathigiti Michali G. Merakli.

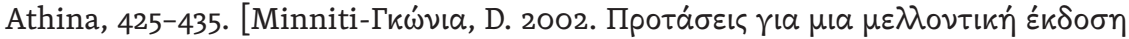

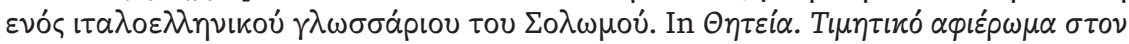

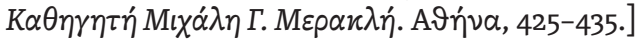

Pavlou, K. 2015. Le premier projet d'écriture des Libres Assiégés de Dionysios Solomos: vers une démarche génétique. In K. Pavlou - G. Pilidis (eds.), Autografi Letterari Romanzi e Neogreci: Due Giornate Di Studio in Memoria Di Filippo Maria Pontani: Padova, Accademia Galileiana, 24-25 Ottobre 2013. Padova, 125-157.

Pierazzo, E. 2011. A Rationale of Digital Documentary Editions. Literary and Linguistic Computing 26/4, 463-477 [online]. Available from: https://doi.org/10.1093/llc/fqro33 [2 March 2020].

Pierazzo, E. 2015. Digital Scholarly Editing. Theories, Models and Methods. Farnham. 
Politis, L. 1938. Gia tin ekdosi tou Solomou. Nea Estia 23, 731-735. Also in Politis, L. 1985.

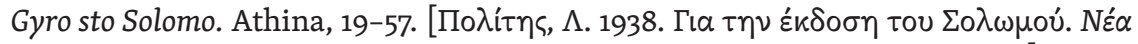

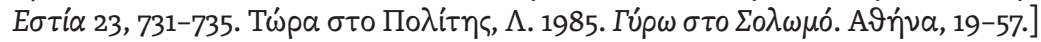

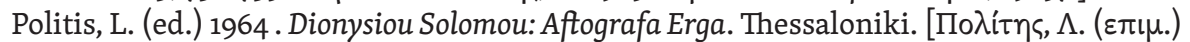

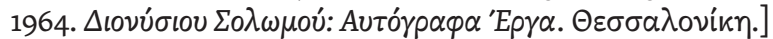

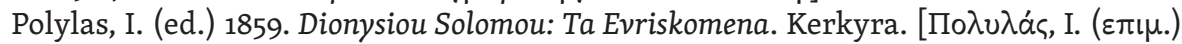

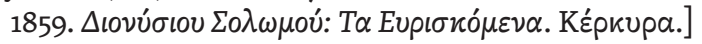

Rehbein, M. - Gabler, H. W. 2013. Reading Environments for Genetic Editions. Scholarly and Research Communication 4/3 [online]. Available from: https://doi.org/10.22230/ src.2013v4n3a123 [2 March 2020].

Sahle, P. 2016. What Is a Scholarly Digital Edition? In M. J. Driscoll - E. Pierazzo (eds.), Digital Scholarly Editing: Theories and Practices. Cambridge, 19-40 [online]. Available from: http://dx.doi.org/10.11647/OBP.0095.02 [2 March 2020].

Sahle, P. et al. (eds.) 2020. A Catalog of Digital Scholarly Editions [online]. Available from: https://www.digitale-edition.de/exist/apps/editions-browser/about.html [16 November 2020].

TEI Consortium (eds.) 2020. Guidelines for Electronic Text Encoding and Interchange (Version 4.0.o). [Last modified 13 February 2020]. Available from: http://www.tei-c.org/ Guidelines/P5/ [2 March 2020].

Tiktopoulou, K. 2003. Dyo epimnimosyna solomika poiimata: 'Eis to thanato tou Lord Baïron' kai 'Nekriki Odi II'. Analytiki kai christiki ekdosi. PhD. Thesis. Thessaloniki. [Tıктотоú-

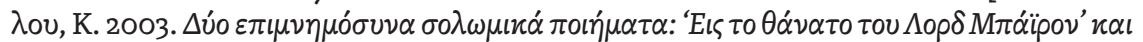

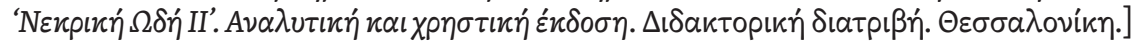
Tiktopoulou, K. 2015. Il problema ecdotico delle poesie incompiute di Dionisios Solomos. In K. Pavlou - G. Pilidis (eds.), Autografi Letterari Romanzi e Neogreci: Due Giornate Di Studio in Memoria Di Filippo Maria Pontani: Padova, Accademia Galileiana, 24-25 Ottobre 2013. Padova, 101-123.

Tiktopoulou, K. - Politi, M. - Kechagioglou, G. - Tsantsanoglou, E. (eds.) 1998-2012. Dio-

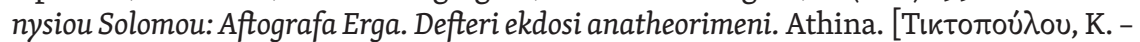

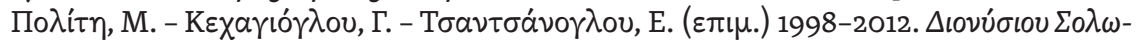

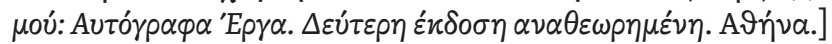

Tsantsanoglou, E. 1982. Mia lanthanousa poiitiki synthesi tou Solomou. To aftografo tetradio

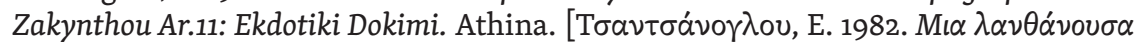

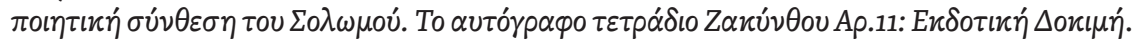
AЭท́va.]

\section{Acknowledgements}

This research is co-financed by Greece and the European Union (European Social Fund ESF) through the Operational Programme «Human Resources Development, Education and Lifelong Learning 2014-2020» in the context of the project "Digital Edition Of Solomos' Manuscripts, Pilot Scholarly/Genetic Edition And Concordance Of Italian Words" (MIS 5005199). 